\title{
BREVE TEORÍA DE LA LECTURA NATURAL ${ }^{1}$
}

\author{
BRIEF THEORY OF NATURAL READING
}

\section{Manuel GONZÁLEZ DE ÁVILA}

Universidad de Salamanca

deavila@usal.es

Resumen: Aunque son muchas las maneras de leer, solo una parece crear al lector: la que en este artículo se califica, recurriendo a una licencia irónica, de natural. Dicho modo lector exige sin duda movilizar el cuerpo para reconstruir presencia a partir del lenguaje, pero también, y ante todo, creer en lo leído y confiar en quien lo ha escrito como comprometedoras condiciones de posibilidad cuasi-trascendentales de esa experiencia lectora.

Palabras clave: Lectura. Presencia. Cuerpo. Creencia. Confianza.

Abstract: Although there are many ways of reading, only one seems to create the reader: the one that in this article is considered, resorting to an ironic license, as natural. This reading mode undoubtedly requires mobi-

\footnotetext{
${ }^{1}$ Este artículo se enmarca en el proyecto I+D Inscripciones literarias de la ciencia: cognición, epistemología y epistemocrítica (ILICIA), Ministerio de Economía y Competitividad, FFI2017-83932-P.
} 
lizing the body to reconstruct presence from language, but also, and above all, believing in what has been read and trusting in whoever has written it, as compromising and quasi-transcendental conditions of possibility of that reading experience.

Key Words: Reading. Presence. Body. Belief. Trust.

\section{1. "SOLO SE LES OCURRE A LOS TEÓRICOS DE LA LITERATURA..."}

1.1. Son numerosas las teorías de la lectura. Cada corriente de pensamiento lingüístico o literario sostiene la suya, explícita o implícita, pero la mayoría arrastra un sesgo escolástico e intelectualista. Así sucede con la teoría de la recepción, con la de la respuesta lectora, con la deconstructiva, etc. Quizá solo aquellas que se apoyan en las neurociencias y en las ciencias cognitivas ${ }^{2}$ están hoy en condiciones de evitar ese sesgo, aun a costa de incurrir en otro: el de pensar el acto lector casi exclusivamente desde el biologismo, siendo la lectura, como parece, una práctica eminentemente cultural; e incluso la práctica cultural por excelencia para nosotros, los hijos platónicos - y no socráticos- del escrito.

1.2. Hay que llamarse Roman Ingarden para mantener, desde la academia, que únicamente a los teóricos de la literatura se les ocurre desechar la plena y efectiva experiencia de la obra literaria, tal y como esta se constituye en la conciencia del lector, y ocuparse exclusivamente de estructuras verbales y de rasgos de estilo (2005: 118; 333). O que ser Pierre Bourdieu para tildar, desde el Collège de France, de "filologistas" — amparándose en M. Bajtín— las lecturas que tratan los textos literarios

\footnotetext{
${ }^{2}$ A propósito de la cognición lectora, y de sus fundamentos neurofisiológicos, pueden consultarse el monográfico de Poetics Today preparado por Richardson y Steen (2002) y las investigaciones de Dehaene (2007) y de Wolf (2008). A ella atienden también en la presente publicación los textos de Gamoneda, López de Silanes, Bermúdez y Patoine.
} 
como cadáveres destinados a la disección en lugar de como obras vivas, en las que el autor y la sociedad hacen apuestas capitales (1980: 34; 2001: 59-60). O que responder por Ricardo Piglia para sugerir, con una doble legitimidad de escritor y de profesor, que en la crítica literaria podría verse un tipo de lectura criminal, en la que se lee un libro contra otro lector (Piglia, 2005: 35), y se instrumentaliza el texto con fines de competición social. Pero lo que no cabe poner en cuestión es que si bien hay múltiples lecturas — porque el ser se lee de muchas maneras, además de decirse de otras muchas (Aristóteles) — la que menos suele interesar a los estudiosos es justamente la más practicada, esto es la lectura ordinaria. Una lectura ni técnica ni profesional a la que, siguiendo la tradición fenomenológica, sería lícito - aunque ambiguo- calificar de "natural", como se habla de "lógica natural" para distinguir los recursos argumentativos pertenecientes a las lenguas naturales de las arquitecturas deductivas de los lenguajes lógico-formales. Leer naturalmente es leer inocentemente o, lo que viene a ser lo mismo, leer para vivir el acontecimiento del sentido en el acto lector.

1.3. Sería posible dudar de que exista semejante lectura natural o ingenua, ya que no solo se aprende con trabajo a leer, sino que también se programa y se evalúa socialmente la lectura, con muy diversos procedimientos y en el interior de estrictos marcos normativos (el sistema de enseñanza y el campo cultural, fundamentalmente) $)^{3}$. Ahora bien, el tan a menudo evocado "milagro" del acto lector, que nos hace cambiar de mundos con solo abrir las páginas de un libro, es un fenómeno semiótico que, una vez dominada su mecánica, se produce con una espontaneidad insólita. Para el lector habitual de obras figurativas - y figurativa es la mayor parte de la literatura, salvo algunas manifestaciones líricas, y aun estas...-, procesar el texto equivale a entrar, inmediata e irreflexivamente, en un universo paralelo fabricado de palabras pero que se impone a nuestra percepción, y

\footnotetext{
${ }^{3}$ Ver, en este mismo número, el texto de Mirko Lampis, "La insostenible soledad de la lectura". No estará de más insistir en que "natural" debe entenderse, aplicado a "lectura", como una provocación, puesto que no hay lectura en la naturaleza. Lo "natural" en la lectura no es sino una "segunda naturaleza", intrínsecamente cultural.
} 
donde se genera abundante experiencia, sensible, emocional y cognitiva. Sobre el poder que esa experiencia tiene de modificar nuestra existencia, o de producir existencia sin más, ya se ha escrito muchas veces - "No lean para divertirse, como leen los niños, ni para instruirse, como leen los ambiciosos", recomendaba Flaubert, "sino para vivir" (2014: 5229)—. Con todo, lo escrito nunca resulta suficiente, en vista de que numerosas lecturas filológicas o escolásticas siguen empeñadas en neutralizar la constitución del texto literario en tanto objeto estético con el fin de mejor reducirlo a artefacto protocolario, y de ignorar así la comprometida dimensión vivencial de la lectura.

1.4. No es el caso, claro, de los escritores, que si lo son es porque antes han sido lectores ingenuos o intuitivos, atrapados desde muy pronto en la bulliciosa red de los sentidos textuales; y capaces, como se lo desea Italo Calvino a sus personajes en Si una noche de invierno un viajero, de "recobrar una condición de lectura natural, inocente, primitiva", renunciando a "desgarrar las páginas con análisis intelectuales", para "absorber las frases en los circuitos de la mente y transformarlas en fantasmas interiores, en lo que es personal e incomunicable". Esa es la lectura que incita al lector a serlo, que lo incorpora, cogiéndolo por la mano - por el cuerpo, diremos_-, al campo literario; la que lo empuja a apreciar la lectura e incluso, con el tiempo, a ser lectura.

1.5. Acaso no haya muchos investigadores dispuestos a confesar que alguna vez leyeron así ${ }^{4}$; o que aún lo hacen cuando, abandonándose a

\footnotetext{
${ }^{4}$ Terminado el presente texto, hemos conocido estas impagables declaraciones de Pierre Bourdieu, cuya transcripción aquí es obligada: “(...) los autodidactas dan testimonio de una especie de necesidad de lectura que de cierto modo la escuela destruye para crear otra, con otra forma. Hay un efecto de erradicación de la necesidad de lectura como necesidad de información: aquella que toma el libro como depositario de secretos, de secretos mágicos, climáticos (con el almanaque para prever el tiempo), biológicos, educativos, etc., que considera el libro como una guía de vida, como un texto al que se le pide un arte de vivir, siendo su modelo por excelencia la Biblia. Pienso que el sistema escolar tiene el efecto paradójico de desarraigar esta expectativa -cabe alegrarse por ello o deplorarlo-, esta expectativa de profecía, en el sentido weberiano de respuesta exhaustiva a todos los problemas de la existencia. El sistema escolar desalienta esa expectativa, y al mismo
} 
la creencia en lo leído, recuperan, contra todo escepticismo profesional, la actitud natural ante la lectura ${ }^{5}$. Tal resistencia se diría lógica: que el lector se adhiera a lo que se lee, al menos en la primera fase de la experiencia lectora, les suele parecer a los especialistas ya una evidencia (Todorov, 1978: 17), ya un misterio (Charles, 1998: 26). Nosotros pensamos que dicho modo de leer no es ninguna de las dos cosas, sino una compleja práctica cultural, constitutiva de una forma de vida, que merece ser explorada, y que hoy puede entenderse con la ayuda de la semiótica y, en cierta medida, de las ciencias cognitivas. A ello dedicaremos las próximas páginas.

\section{CAMBIAR DE MUNDOS}

2.1. Nada más fácil y agradable, para el lector, que ponerse a leer. Sin embargo, es esa una operación que la opinión común y la promoción cultural reputan, con justicia, de "mágica": al abrir el libro, quien lee se desprende de su mundo e ingresa en un contramundo o antimundo (Handke, 1990: 19) que lo conmocionará, y con el que sostendrá una intensa relación, carnal y espiritual a la vez. En efecto, además de absorber su atención sensible y de estimular sus pasiones, el contramundo leído le revelará valores y cualidades que el lector pena por encontrar en la cotidianidad (Ingarden, 1983: 247-252); juntos, valores y cualidades le permitirán intuir algo así como un más allá del sentido, como una suerte de ultrasentido o de anticipación de una vida verdadera, ya no del todo profana (Greimas,

tiempo aniquila cierta forma de lectura. Uno de los efectos del contacto ordinario con la literatura cultivada es el de destruir la experiencia popular, para dejar a la gente formidablemente desposeída, es decir entre dos culturas: entre una cultura originaria abolida y una cultura cultivada que se ha frecuentado lo suficiente como para no poder ya hablar del tiempo y de la lluvia, como para saber todo lo que no hay que decir, sin tener ninguna otra cosa que decir. Y pienso que este efecto del sistema escolar, que jamás se menciona, es del todo sorprendente cuando se lo reconstruye en relación con los testimonios históricos [sobre la lectura] que nos han sido legados." (1984: 179).

${ }^{5}$ Con mayor explicitud, el lector natural no efectúa, al leer, ninguna especie de epojé, de suspensión de la creencia o de puesta entre paréntesis de lo sentido y de lo pensado: se limita a experimentarlo, como veremos, en carne propia. 
1987: 78), aunque tampoco inequívocamente sagrada. No es extraño, por tanto, que el lector vocacional quede afectado al leer, y que la lectura sea el evento más relevante de su forma de vida, aun cuando a menudo no pueda dedicarle más que algunos ratos perdidos.

2.2. Durante el tiempo que dura la fractura estética impuesta por el leer, se reduce hasta casi desaparecer la diferencia entre el sujeto y el objeto, entre la conciencia lectora y el contramundo o antimundo leído. Un ejemplo de ello es el conocido relato de Julio Cortázar Continuidad de los parques, en el que la ficción ingresa en la realidad desde el mismo momento en que la realidad se pone en manos de la ficción a través de la lectura. Si tanto es el poder del texto literario que por su medio llegan a confundirse los niveles ontológicos, no sorprenderá tampoco que la palabra "magia" se aplique literalmente a la lectura, ni que la conmoción del lector tenga un alcance cuasi sacramental ${ }^{6}$. Naturalmente, pareja comunión entre el que lee y lo que lee exige condiciones sociales de posibilidad previas; y ni todo el mundo la desea, ni es la única manera de leer. Pero sí resulta la más significativa, por culminar en ella la vivencia de la lectura espontánea que forja al lector y que le hace ser lo que es en cuanto lector; y, cuando cristaliza en forma de vida, en tanto sujeto social sin más. Porque, como se sabe, el lector no regresa inalterado de la lectura natural — si es que se regresa: en el cuento de Cortázar no lo hizo —. Y eso aun habiendo, paradójicamente, reforzado también su propia identidad tras la actuación lectora.

\section{FÍSICA Y METAFÍSICA DEL SENTIDO}

3.1. Ahora bien, el mundo es físico, y el sentido, del que está hecho el contramundo o antimundo en el que entra el lector por la puerta de la lectura, no. O, al menos, el sentido no semeja tener de físico sino lo que tiene de material el soporte de la escritura, el papel y la tinta, o la pantalla y el píxel. Sobre tal presunta evidencia empírica se apoyan aquellos que

\footnotetext{
${ }^{6}$ Recuérdese que el campo literario absorbió, desde el siglo XIX, algunos de los valores hasta entonces propios del campo religioso (Viala, 1985; Bourdieu, 1992).
} 
han divulgado la idea, manida en el campo de la teoría de la literatura, de que la lectura es solo un ejercicio de la imaginación; y lo leído, una ficción.

3.2. Con todo, el amor de la lectura no está condenado por necesidad al desengaño ontológico - a la desventajosa comparación de la apariencia con el ser-, ni a la desilusión lógica —a la improbable confrontación de la ficción con la verdad-. Justamente, los semiólogos actuales, obligados a formarse en neurociencias y en ciencias cognitivas o, lo que es lo mismo, a practicar un poco el materialismo científico, se han propuesto devolver el mundo a las palabras y las palabras al mundo, e incorporar la verdad del ser a dicha restitución del vínculo originario de la physis con el logos (Petitot, 2011). El objetivo principal de la semiótica contemporánea es por ende suturar la herida nominalista que desde hace demasiado tiempo separa la sustancia y la forma de los signos, herida por la que se escapa la esencia misma del sentido, la "vehemente trascendencia ontológica" del lenguaje (Ricoeur, 1975: 321). Y si los investigadores literarios quieren estar a la altura de ese proyecto, parece lógico esperar que den cuenta de la lectura natural antes que de las lecturas profesionales; es decir, que expliquen cómo la lectura ordinaria disuelve los límites entre las palabras, el mundo y el ser, haciendo que, para el lector espontáneo, el lenguaje sea el ser enunciándose en presente ${ }^{7}$ (Coquet, 2007: 62-63).

3.3. Pues sucede que, excepto para el lector distanciado, aquel que se niega a constituir el texto como un objeto estético, manteniéndolo - contra la voluntad del propio texto, nos atreveríamos a decir- en su condición primaria de artefacto verbal, la escritura de la obra literaria figurativa produce y reproduce lo real humano, a lo que está anclada $a b$ origine. Y su lectura produce y reproduce la experiencia de ese vínculo en una permanente demostración de que, para el hombre que lee, el lenguaje es el lugar donde se afirma su aprehensión del mundo, si bien bajo figura estética de contramundo o de antimundo. En esta agregación de uno o dos prefijos al genérico "mundo" compartido se marca la libertad condicional

${ }^{7}$ Formulación cuyo antecedente casi literal es la célebre sentencia de H.-G. Gadamer: "El ser que puede ser comprendido es lenguaje" (2012: 567). 
de la literatura respecto de las estructuras dadas en él.

3.4. Siendo así la ontología para el hombre, ante todo o al menos también, una ontología verbal, se diría deseable que la teoría de la lectura natural oponga el principio de la realidad del lenguaje al principio de la inmanencia del texto; y que ello requiere esclarecer, preliminarmente, de qué modo se funden, en la logosfera humana, el ser y la palabra o, desde el punto de vista de la ciencia, la materia-energía y el signo.

\section{CONVOCAR LA PRESENCIA}

4.1. Materia y energía son, en efecto, los constituyentes básicos de un mundo descrito por la ciencia como un continuo en movimiento, como un verdadero campo de fuerzas, anterior a toda palabra y condición de posibilidad de esta. Un campo de fuerzas que el cuerpo explora, de entrada, mediante los sentidos, y a cuyas modulaciones la conciencia atribuye después valencias eufóricas o disfóricas, en función de si se siente atraída o repelida por ellas; de si allí anticipa, por ejemplo, una promesa o una amenaza. De esta suerte surgen las primeras articulaciones semióticas que hacen del campo de fuerzas un campo de presencia, en el cual hay algo que concierne al cuerpo-conciencia, y a lo que por ello mismo este último convierte en su campo de percepción.

4.2. Pero el cuerpo-conciencia hace algo más que vincularse sensorialmente con el mundo y que percibir en él indefinidas presencias, sugestivas o intimidatorias. En un tercer momento, trabajando sobre los umbrales de la materia y de la energía, el cuerpo-conciencia fuerza la aparición de figuras cuyas valencias latentes se adensan hasta transformarse, para él, en los valores del significado. De ese proceso de semiotización del entorno emergerán al unísono, por una parte, un genuino sujeto, una instancia enunciativa, y por otra su necesario correlato, un mundo ya no solo sensible y perceptible, sino también enunciable; esto es, un campo de presencia transmutado en campo de discurso. Dicho de otra guisa: el cuerpo-conciencia, que empieza tomando posición, sensorial y perceptiva, 
en su campo de presencia, tras semiotizarlo pasa a referirse a él y a referirlo mediante el gesto y la palabra, confundidos en el momento inaugural del lenguaje, por necesidad indeterminable.

4.3. El anterior esbozo de la génesis de la presencia, y de su sentido para el hombre, podría entenderse, si se quiere, como un pequeño mito de origen incorporado al imaginario epistemológico de la teoría semiótica. Un mito que sirve, por mor de la paradoja, a la ciencia, pues explica, aun vagamente, el prodigioso entrelazamiento inicial de la materia-energía y del signo, del mundo y la palabra, antecedente necesario para el constatado y mil veces aludido milagro de la lectura como experiencia de una realidad que se troca en lenguaje, y de un lenguaje que deviene realidad, tal las dos caras aparentes de una cinta de Moebius.

4.4. Pareja reversibilidad, la propia del universo humano como continuo semiofísico (Petitot, 2011), hace de la presencia del lenguaje, de la llamada existencia semiótica, una verdadera donación de la presencia del mundo, después de que esta haya sido dada, una primera vez, por la percepción. Sobre la segura interrelación de esas dos presencias, la de las palabras y la de las cosas (objetos, estados del mundo, acontecimientos), vendrá a apoyarse otra imprescindible seguridad posterior del sujeto semiótico: la de que, mientras sea sujeto, podrá expresar lo real, el espaciotiempo significante, remitiéndolo a sí mismo como centro enunciativo. Una seguridad con consecuencias ontológicas que, a menudo, se manifiesta más rotundamente para la vivencia poética que para la inteligencia filosófica. Jorge Guillén escribe, en Aire nuestro:

\author{
Heme aqui solidario \\ del día tan repleto, \\ sin un solo intersticio \\ por donde se deslice \\ la abstracción elegante de una duda. \\ Duden con elegancia los más sabios. \\ Yo,
}


no ;Yo sé muy poco!

Por el mundo asistido,

me sé, me siento a mí sobre esta hierba

tan solicitamente dirigida.

¡Jornalero real!

También de mi jornada jornalero,

voy pisando evidencias,

verdores.

4.5. El trabajo del sujeto, en este caso del sujeto poético, de ese "yo" aislado por el encabalgamiento versal y sobre el que pivota todo el discurso, es "pisar evidencias"; y, claro está, escribir que se las pisa, para hacer sentir y percibir que se pisan evidencias durante la lectura. Una reviviscencia de la presencia del mundo en la presencia del texto que eleva la escritura y la lectura, íntimamente relacionadas como veremos, a un equivalente de la experiencia del ser; a un fenómeno, en suma, esbozado así por otro poeta, Fernando Pessoa, en El libro del desasosiego:

La literatura es [...] la realización sin la mancha de la realidad [...] Creo que decir una cosa significa conservarle la virtud y despojarla del terror. Los campos son más verdes en el decirlos que en su verdor. Las flores, si se describen con frases que las definan en el aire de la imaginación, tendrán colores de una permanencia que la vida celular no permite [...] En la palabra está todo el mundo contenido, y en la palabra libre está contenida la completa posibilidad de decirlo y de pensarlo (2002: 246).

4.6. Claro que no es imprescindible ser un poeta perdidamente abierto a la presencia del mundo, como Guillén, ni tampoco a la presencia del lenguaje, como Pessoa, para apreciar la "realización" del ser en la 
reversibilidad del mundo y del lenguaje. Diecisiete siglos antes de Cristo, alguien le escribió a su corresponsal en una aldea de Mesopotamia (apud Manguel, 2018: 3):

Bulattal me ha traido tu mensaje. Tus palabras me han llenado de placer. Tuve la impresión de que tú y yo nos habiamos encontrado y de que nos habiamos abrazado.

Y ese mismo abrazo se reproducirá veinte siglos después de Cristo, cuando un publicitario pergeñe el siguiente cartel-slogan para los correos tradicionales, dando prueba de que, para los hombres, de la escritura brota la más intensa vivencia de la presencia:

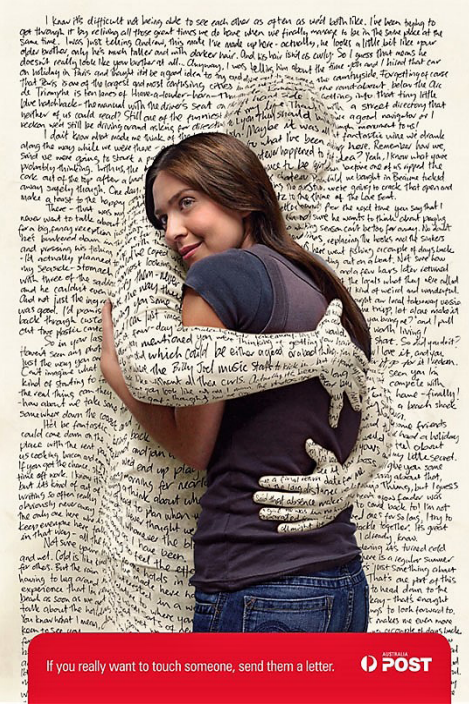

Figura 1. Publicidad de los correos australianos.

4.7. La presencia, primer modo de significación de lo que existe (Fontanille y Zilberberg, 1998: 91), no es sin embargo continua ni uniforme, puesto que si lo fuera el sujeto retornaría a su (mítica) indiferenciación originaria con el mundo, y cesaría de ser sujeto; y, por tanto, dejaría de ha- 
ber propiamente mundo, y también intención y lenguaje. La presencia está entreverada, primero, de ausencia, su correlato dialéctico; de hecho, en instituir lo presente sobre lo ausente, y viceversa, consiste la enunciación (Lacan: 1966: 237-322). La presencia instituida es graduada después por la instancia enunciativa de suerte que las apariciones textuales resulten relativamente lejanas o cercanas, densas o ligeras, según un juego de modulaciones que confiere a la manifestación verbal una profundidad estratificada en distintas capas de existencia sensible. Estas, las capas de existencia sensible, aun teniendo una naturaleza continua, han de verse categorizadas a la vez por decisión de quien escribe y de quien lee, traduciéndose en niveles de existencia semiótica. De lo contrario, el texto y las palabras que lo componen no podrían ser inteligibles, estabilizarse como objeto cognitivo.

4.8. La categorización de la presencia distingue en ella cuatro grados de proximidad o de distancia, de concentración o de disolución, cuatro modos de existencia semiótica, articulados en sistema sub-lógico:

Real

Virtual

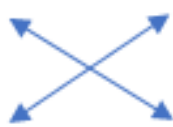

Actual

Potencial

- Grado real: el de lo que es efectivamente;

- Grado virtual, contrario del primero: el de lo que solo puede llegar a ser;

- Grado actual, contradictorio del virtual y complementario del real: el de lo que está en trance de ser, estación de paso entre lo virtual y lo real;

- Grado potencial, contradictorio del real y complementario del virtual: el de lo que una vez fue y quedará pronto archivado como virtual. 
Siendo, claro está, los grados actual y potencial también contrarios entre sí, como lo son el real y el virtual (Fontanille, 2003: 67-69).

4.9. Recurramos de nuevo, para ejemplificarlos, a las tesis sobre la lectura que Italo Calvino despliega en Si una noche... Su narrador-personaje afirma que leer es siempre "enfrentarse, a través del texto, a alguna otra cosa". Una cosa que, o bien forma parte de un mundo "pensable e imaginable" (esto es, virtual), o bien "ha existido y ya no existe" (es decir, que ha pasado a ser potencial), o bien "se teme o se desea" (verbigracia, que ya es inminente, pues la emoción actualiza esa cosa), estando entonces "a punto de ser" (o sea, cercana a realizarse); y que, cuando se realiza, introduce al lector en "una esfera suspendida en otro tiempo y otro espacio" (Calvino, 2013: 89, 219).

4.10. Así es como la lectura del texto figurativo ejecuta la función simbólica, regulando las escalas interdefinidas de la presencia/ausencia de un mundo en las palabras y de las palabras en el mundo. El maestro japonés Yosa Buson (1715-1783) escribió estos dos haikus que exponen el enlace entre presencia y ausencia, discursivas y ontológicas, visto desde el prisma del transcurso del tiempo:

Crepúsculo de cerezas.

También hoy se ha convertido

en pasado.

\section{Los días lentos}

se apilan, evocando

un viejo antaño.

En el primer poema la plenitud sensible del hoy, cuya plasmación es la clave de tantos haikus (un "crepúsculo de cerezas"), es captada sin embargo en su inexorable fluir hacia atrás, en su paulatino mudarse en la inanidad de un ayer ya solo potencial ("se ha convertido en pasado"). En el segundo poema, otro pretérito aún más hundido en la distancia temporal 
("un viejo antaño"), y por tanto puramente virtual, es atraído hacia el ser por un acto de "evocación" demorada que lo actualiza, oponiéndose a su vacuidad, y que instala, en lugar de esta, la carencia de lo que se recuerda y se echa de menos. La articulación de esas cuatro formas de existencia - la plenitud real del hoy, la inanidad potencial del ayer, la vacuidad virtual de un pretérito aún más "viejo", y la carencia actual - en un presente de nostálgicos "días lentos", implanta en la lectura toda la profundidad posible para la experiencia a la vez del tiempo y de la presencia, y para la del sentido asociado al tiempo y a la presencia ${ }^{8}$.

4.11. Naturalmente, los fenómenos a que da lugar la gradual convocación de la presencia, por medios simbólicos, en la escritura figurativa, dependen en su totalidad de un modo de lectura que reconoce en los textos cuanto tienen de energeia, de vivencia del sentido durante el acto lector. Quien lee ha de lograr reconstituir la presencia amarrando la realidad a su descripción verbal o, como diría Ingarden, superando el mero registro mecánico de las palabras del texto para aprehender los objetos intencionales a los que aquellas se refieren, sin los cuales las palabras se vacían de toda denotación y de toda facultad para forjar un mundo o contramundo; y los lectores quedan privados de toda competencia para asir, como sucede durante la lectura natural, "las cosas mismas" implicadas en las oraciones (Ingarden, 2005: 59-60).

\section{LA DOCILIDAD DE LA LECTURA}

5.1. La captación de los referentes intencionalmente denotados por las palabras del texto (objetos, estados de cosas, sucesos) ocurre porque el lector se representa la presencia del mundo que el autor convoca en la escritura, en un acto de re-producción, corporal y mental, segundo con

\footnotetext{
${ }^{8}$ Ver una ampliación de este punto en Fontanille y Zilberberg (1998: 91-111). Cabría comparar también significativamente los desarrollos semióticos sobre la presencia con ciertas tesis convergentes de la "estética del aparecer" en la obra de Martin Seel (2011).
} 
respecto al primero, el ejecutado por el escritor. Ese acto resulta segundo cronológica, pero también fenomenológicamente, porque el seguir a la escritura es asimismo, etimológicamente, secundarla — "secundar" procede de la misma raíz latina que "seguir", sequere; y esta del indoeuropeo *sekw, de donde se deriva igualmente "signo"- El lector, así, deviene una réplica del autor. Un autor que, mediante la escritura, "capta el acontecimiento en una forma" (Handke, 1990: 39), con el fin de que el lector, durante la lectura, "haga renacer el acontecimiento y la experiencia del acontecimiento" (Benveniste, 1976: 25).

5.2. La docilidad que tal comportamiento supone se debe a que leer y escribir son prácticas gobernadas por unas mismas reglas, perceptivas y cognitivas, las reglas que regulan la transposición semiótica de su fenómeno propio, la encarnación verbal de una experiencia de conciencia. La psicología del lenguaje, en efecto, nunca ha sostenido nada diferente: la producción y la recepción de los enunciados verbales son solidarias, de suerte que comprender ambas requiere del concepto, es cierto que matizado, de especularidad (Schaeffer et Todorov, 1995: 421). Primero incluso que ella, la fenomenología ya había insistido en que la obra literaria era una norma para su lector, quien debía ante todo aceptar su guía y entregarse a la lectura desde "la fidelidad", "la sumisión" e incluso "la alienación", permitiéndole que "se impusiera" a él hasta "reprimir su imaginación y su entendimiento" (Dufrenne, 1953a: 86; 1953b: 661). La lectura queda en consecuencia sometida a un extraño contrato cuyos términos no pueden sino generar cierto malestar en la conciencia política contemporánea. Escuchemos a otro escritor, P. Quignard (1997: 40):

Es sorprendente que un individuo se apodere de un pequeño paquete de páginas impresas. Es notable que acepte sin embarazo el punto de vista de otro individuo. Es curioso que asuma justificar, leyendo, el empleo unilateral de una lengua [...] desertada por su mismo autor, el uso de un código que jamás se explicita ni se domina, y cuyas leyes no toleran que las ponga en discusión. En nuestra lengua, se le llama un lector. 
5.3. Descartado que el escritor esté en condiciones, como conjetura P. Quignard, de hacer un uso plenamente "unilateral" de la lengua - lo que casi equivaldría a refrendar la existencia de un lenguaje privado, algo que ya Wittgenstein, y el mismo Marx, habían tenido por imposible-, el autor francés probablemente acierta en casi todas sus otras afirmaciones. Y, en particular, en lo implicado por estas: que el lector, antes de nada, acepta y asume lo que lee, salvo que opere en modo crítico radical. Es más, aún en este último caso, la crítica será siempre un ejercicio posterior a la reviviscencia intencional del sentido de lo leído; un sentido que, solo luego, se someterá a escrutinio distanciado.

5.4. La lectura natural, entonces, es una práctica a la que se entrega un sujeto intencional, el lector, que camina sobre las huellas dejadas por otro sujeto intencional, el autor. Las intencionalidades de uno y otro convergen en el texto literario, un objeto estratégico resultado de una programación cognitiva, y capaz de dar forma a la experiencia de ambos, a la experiencia en producción del que escribe y a la experiencia en recepción del que lee. Y todo ello a partir de su singular identidad fenomenológica como artefacto verbal (Iser, 1995: 195-286; Ouellet, 2000: 345-346).

5.5. Porque una de las hipótesis más insuficientes de muchas teorías de la lectura es la que ve, lo hemos recordado, al texto indefenso ante el lector, haciendo de él un blanco para sus proyecciones, ya psicológicas (sus emociones), ya sociológicas (su ethos y su habitus). Antes bien, el sentido primario del texto está materialmente inscrito en sus signos y hecho de un acuerdo social que precede a cualquier atribución por parte del lector: el lector debe someterse voluntariamente a él, que se le impone como primer paso para todo tipo de lectura. La vivencia del sentido trasciende así la experiencia psicológica (Ingarden, 1983: 94-103) y desafía, o al menos sacude, las determinaciones sociológicas del lector, contribuyendo a modificarlas. Las estructuras constatables de la textualidad son no solo la mediación concreta entre el productor y el receptor del texto, sino también un eficaz instrumento colectivo que modela a la par la percepción y la 
autopercepción psicológicas y sociales del lector, como antes ha modelado las del escritor.

5.6. Sería engañoso, por tanto, considerar la lectura ordinaria como subjetiva (impredecible) o como objetiva (predecible). Su intelección reclama más bien otro balance distinto entre el sujeto y el objeto, entre el lector y el texto, cuya distinción parece difuminarse mientras se lee (Iser, 1995: 188). Y ello tanto más cuanto que el lector es, genéticamente, aquello en que lo ha convertido su larga práctica lectora dentro del campo literario. Una práctica que alimenta esa verdadera forma de vida, coherente y persistente, a la que nos hemos referido, y que crea y recrea los modos de ser y de hacer del sujeto lector, en los que lo psíquico y lo social se subsumen mutuamente hasta resultar inseparables (Adorno y Horkheimer, 1989, 2016; Luhmann, 2005).

5.7. Si el texto es un dispositivo estratégico — lo esencial de escribir, y de corregir lo escrito, no consiste sino en buscar un determinado efecto de lectura - , habrá que indagar la manera en la que el lector acepta sus estrategias para regenerar el sentido y reconstituir, según los distintos grados ya consignados, la presencia de un estado del ser, el principal de los efectos de lectura de los textos figurativos. La primera y necesaria aceptación del texto por el lector va seguida de una inmediata entrada en colaboración con él: el lector deviene instancia de co-enunciación, de coconstrucción semiótica, porque le presta al texto su cuerpo y su mente para que este desencadene sobre ellos una mimesis, una identificación activa, de entrada sensible, y después pasional y cognitiva, con los acontecimientos sensibles, pasionales y cognitivos figurativamente elaborados en la textualidad. El lector interioriza las situaciones del mundo de las que el texto da testimonio con su flujo verbal: leer es una experiencia que consiste en compartir las formas de otra experiencia que han quedado impresas, en tanto signos - sus trazos o huellas-, en el objeto semiótico que provoca y dirige la experiencia, el texto (Fontanille, 2011: 169-181).

5.8. La psicología dispone, para designar tan extraordinario suceso, del concepto de "experiencia vicaria" (Bandura, 1997). La fenomenología, 
a pesar de sus originarias disposiciones antipsicologistas, no se refiere a la experiencia estética, y a la lectura en general, en términos muy alejados de los anteriores, lo que indujo a M. Dufrenne a afirmar que la disciplina era una "psicología sin psicologismo" (1953a: 6) —es decir, sin relativismo subjetivista- En cuanto a la semiótica, cada vez más deudora de la fenomenología, y en convergencia parcial con las ciencias cognitivas, una vez trascendido su mito fundacional de la inmanencia del sentido, ya no le resta sino escuchar la lección que sobre el vínculo escritura-lectura le dan a menudo los mismos autores literarios, menos cargados de prejuicios escolásticos que los investigadores. Por ejemplo, del novelista G. Saunders es esta lúcida meditación sobre el famoso milagro de la lectura (2013:20):

No me conformo con emociones ligeras, quiero que sientas que estamos leyendo el mismo texto hombro con hombro y que si yo me inclino, tú te inclines, y que si la reina muere y digo que me da lástima, te dé lástima a ti también. Finalmente, las relaciones entre el escritor y sus lectores resultan conmovedoras y profundas porque, aunque sean sujetos diferentes, no lo son tanto: la frontera cae en si yo, escritor, le hago algo a la reina que a ti, lector, te obligue a retorcerte. Se trata de una intimidad cruzada entre seres, y creo que debe tener una representación neurológica: si doy un detalle físico, como "su ropa olía a grama recién cortada”, y tú tienes la misma sensación, supongo que lo que se disparó en mi cerebro al pensarlo es lo mismo que se dispara en el tuyo al leerlo. Es sorprendente, en especial cuando el autor lleva cien años muerto. Esa conexión íntima es la literatura.

5.9. Hoy ya es de conocimiento común la "representación neurológica" de dicha "intimidad cruzada entre seres" por la que se pregunta 
Saunders, es decir su soporte fisiológico: las llamadas "neuronas espejo". No parece por tanto necesario insistir sobre ello9. Lo que aquí más bien debería interesarnos es describir el efecto del sustrato neurofisiológico en la práctica lectora. Un efecto al que el mismo P. Handke caracterizó como una "unión" del lector con el escritor que "compuso el texto"; o, en metalenguaje semiótico, una mimesis lectora. A ella el autor alemán asignó después la alta misión de “otorgar luz" y de "lograr el día” (1990: 86, 125; 1994: 29, 58); esto es, también en metalenguaje, de realizar el sentido.

5.10. Es legítimo considerar la mimesis, operación clave en la recepción de un texto, y no únicamente en su producción —el modo tradicional de entenderla-, como un universal antropológico (Taussig, 1993; Storey, 1996). La recepción de la literatura figurativa pasa por una identificación mimética del lector con lo que lee; ese estado de conjunción sujetoobjeto, lector-texto, constituye y conforma paulatinamente la subjetividad lectora y, aun siendo sus contenidos imaginarios - "ontológicamente heterónomos", precisaría Ingarden (1983: 94)—, resulta, en cuanto estado, tan real como la más concreta de las experiencias ${ }^{10}$.

5.11. Sería oportuno recordar, a este respecto, que si la semiótica ha necesitado introducir el concepto de "realización" del sentido es porque, según ella como según la fenomenología, lo real no se confunde ingenuamente con la objetividad material, ni aún menos con la verdad científica. Lo real, para un ser humano, es experimentar presencia, y las presencias que se experimentan pueden muy bien ser ficticias o inactuales - pasadas o futuras-, etc. (Parret, 2006: 15). La presencia, cuya vivencia es el efecto último de la realización del sentido a través del texto literario, no está sometida ni a la ontología del mundo físico, ni a la lógica del discurso vericondicional sobre el mundo físico. El lector, como el escritor, es un perseguidor de apariencias; el lector, como el artista plástico, es un cazador de las presentaciones o presentificaciones ${ }^{11}$ del ser en las que se cifra,

\footnotetext{
${ }^{9}$ Sobre el particular puede leerse (Rizzolatti y Sinigaglia, 2006).

${ }^{10}$ Como afirma López de Silanes en este mismo número de Signa, la mimesis está fuertemente arraigada en la arquitectura nerviosa.

${ }^{11}$ Husserl distinguía los conceptos de "presentación" y de "presentificación" para dis-
} 
acaso, lo más propio e íntimo del ser. Si la hija de Butades, a la que la leyenda griega atribuye el origen del dibujo, trató de apresar la presencia de su amante marcando con carboncillo la silueta de su sombra en la pared, el escritor y el lector encierran las manifestaciones del mundo, cuyos contornos ciñen mediante palabras, en los textos literarios. Y así el lector es el doble mimético del escritor y a ambos, al igual que al pintor-espectador del célebre relato de Marguerite Yourcenar Cómo se salvó Wang-Fô, les gusta "la imagen de las cosas, y no las cosas mismas" (1998: 11). Una imagen que, según Marcel Proust, "nos encanta y nos decepciona" a la vez, pues aun atesorando la esencia de nuestra relación perceptiva con el mundo, no pasa de ser una apariencia ([1905] 2017: 42).

5.12. "Pintores y poetas nos enseñan de la misma manera", dejó escrito igualmente M. Proust en el mismo ensayo sobre la lectura (41). Parece razonable, con todo, que tan grata enseñanza se mire con suspicacia, al menos a partir de la edad moderna. Ciertamente, de la educación de la subjetividad en la lectura hay visiones favorables como la de Joyce Carol Oates (1987: s/p), quien asegura que el lector conserva la iniciativa y guarda cierta soberanía sobre sí mismo:

La lectura es el único medio a través del cual nos deslizamos, involuntariamente, a menudo sin poder hacer nada, a la piel de otro, a la voz de otro, al alma de otro [...].

Pero también cabe observar, con Schopenhauer, que la alienación exigida por el acto lector, y de la que más tarde dará cuenta la fenomenología, es perjudicial desde el momento en que el sujeto renuncia a su imagi-

criminar el testimonio del ser que proporcionan los sentidos corporales (presentación), fuente para él de toda certidumbre, y las manifestaciones del ser obtenidas a través de medios simbólicos (presentificaciones), sujetas en parte al relativismo cultural (1996: 67 y ss; 2003: 230). Sin poner en cuestión la diferencia ontológica entre uno y otro conceptos, y siguiendo en esto los desarrollos ulteriores de la fenomenología, cabe subrayar la semejanza existencial de ambos, como hicimos al hablar del cuento de J. Cortázar en el que juega a confundir, en la experiencia, los niveles del ser de lo leído y de lo vivido. 
nación y a su entendimiento en beneficio de los del autor (1996: 169-170) —nótese no obstante que el alemán tenía sobre todo en mente la lectura filosófica-:

Cuando leemos, otro piensa por nosotros; repetimos simplemente su proceso mental [...] La lectura nos libera, sentimos un gran alivio cuando dejamos la ocupación con nuestros propios pensamientos para entregarnos a la lectura. Mientras estamos leyendo, nuestra cabeza es, en realidad, un campo de juego de pensamientos ajenos. Y cuando éstos se retiran, ¿qué es lo que queda? Por esta razón, sucede que quien lee mucho y durante casi todo el día, y en los intervalos se ocupa de actividades que no requieren reflexión, gradualmente pierde la capacidad de pensar por sí mismo - como el individuo que siempre va a caballo se olvida de caminar-. Tal es el caso de muchas personas muy cultas. Acaban siendo incultas de tanto leer.

Sentimiento de abandono de sí a un poder exterior, al leer, que Fernando Pessoa, con su inimitable mezcla de pasividad ante el mundo y de activa asunción de dicha pasividad como una opción óptima, resumió en esta lapidaria sentencia: "Leo como quien abdica" (2002: 69).

5.13. La libertad subjetiva del actor contemporáneo, en su faceta lectora, parece encajar un rudo golpe, si se confirma que leer es, de entrada y en sus primeras fases, prestarse a la mimesis, a una adaptación sensible, pasional y cognitiva, del lector a lo que lee. La lectura, en efecto, en cuanto experiencia estética, supone plegarse a ser determinado por el texto; y se diría que ello limita el sentimiento de libertad asociado por convención a las prácticas culturales (Seel, 2010). "Leemos", decía Simone Weil, "pero también somos leídos por otro" (2006: s/p). A cambio de ceder autonomía, el lector participa, ya lo adelantamos, en la lectura como energeia, como movimiento; se mueve con su semiosis viva y en acto, y es movido por ella, dejando atrás el lugar estático del ergon, del mero texto como producto 
objetivado.

5.14. Por otra parte, aceptar que el lector es, en primera instancia, el espejo neuronal en el que se mira el escritor, no reduce tanto su independencia como conduce al establecimiento de una intersubjetividad fraguada en el símbolo compartido. Yuri Lotman lo expresó con palabras que, aun invitando a la reflexión moral, pertenecen estrictamente al discurso científico, y en las que se lee una rotunda y bajtiniana refutación del solipsismo (1996: 91):

El texto como generador de sentido, como dispositivo pensante, necesita, para ser puesto en acción, de un interlocutor. En esto se revela la naturaleza profundamente dialógica de la conciencia como tal. Para trabajar, la conciencia tiene necesidad de una conciencia; el texto, de un texto; la cultura, de una cultura.

A Lotman solo le faltó añadir, como lo hace la ciencia contemporánea, que también el cuerpo necesita, para trabajar, de otro cuerpo. Leer es, justamente, ese diálogo somático entre el cuerpo del lector y el cuerpo del autor - sedes de sus respectivas conciencias intencionales - entablado sobre el terreno firme del texto y de los signoshuellas que en él ha depositado la experiencia de la escritura con el fin de que sean devueltos a la vida por la experiencia de la lectura.

\section{EL CUERPO LECTOR}

6.1. Ya no parecería adecuado, por tanto, que la teoría de la lectura contemporánea siguiera atada ni al idealismo filosófico ni a la sublimación cultural. Si la lectura literaria es una experiencia estética institucionalizada, y si la conciencia explora durante ella todas sus posibilidades, ambos acontecimientos tienen como condición de posibilidadla vivencia inmediata, estésica antes que estética, y corporal antes que intelectual, de la iconización 
encarnada del texto en el lector. Este último ajusta analógicamente su cuerpo propio a lo leído, en un ejercicio de una extraordinaria plasticidad en que se transparenta el sustrato biológico de la mimesis. El lector es a la vez sujeto agente y paciente de un proceso cultural que, literalmente, da forma provisional a su materia y energía somáticas, y que en ellas deja una marca significativa —el imborrable recuerdo de nuestras mejores experiencias lectoras - . Probablemente Johann A. Bengel acertó al encabezar en 1734 su edición del Nuevo Testamento con este consejo: Te totum aplica ad textum, rem totam aplica ad te. Se objetará acaso que tal consigna solo concierne a la lectura de un libro percibido y recibido como sagrado. Y sin embargo, así es también como leemos los grandes textos canónicos de la tradición literaria, y más acá de ellos las obras que realmente nos interesan en tanto lectores naturales: la lectura ordinaria exige un uso del texto, y una entrega a él, cuya credencial decisiva se encuentra justamente en la creencia del lector; en su adhesión, en suma, a una fe en el acontecimiento del sentido textual — lo argumentaremos más adelante-

6.2. Nos detendremos ahora por un momento, aun a riesgo de repetirnos, en el proceso de iconización encarnada, cuya complejidad reclama algunas explicaciones complementarias. Leer requiere, como primer gesto, el que el lector ceda su cuerpo a la corriente del lenguaje. Pero el cuerpo-lector, atravesado por el flujo del texto, también reacciona ante él, adaptándose miméticamente a lo leído; la respuesta sinestésica y kinestésica que se produce vuelve al lector inherente a la presencia del mundo convocada por las palabras, a la manifestación graduada y escalar del ser (Parret, 2006: 200). Dicho de otro modo, el equipamiento somático del lector está habilitado, por evolución cultural, para transformar el campo de presencia discursiva, los indicios verbales esparcidos por el texto, en un campo de presencia sensible, vivenciada, experimentada, hecha cuerpo propio.

6.3. Ese portento estésico, esa animación al leer de un cuerpo medio imaginario medio real, o inseparablemente imaginario y real, 
acontece porque la materia-energía de la carne ${ }^{12}$ ignora el reposo, no menos en la práctica lectora que durante la aprehensión del mundo físico. El dinamismo sensomotor de la vida, su constante y sutil movilidad, reúne, en un haz coherente de percepciones multimodales, originadas en los distintos canales sensoriales, la información semántica proporcionada por el texto y la información sensible procedente del mundo (Fontanille, 2004: 81-121; 2011: 54-85). Y de esta suerte el cuerpo propio del lector, en alerta intencional hacia las palabras, es la continuación consecuente de su carne viva, en tensión intencional hacia los objetos y estados de la realidad física. El sujeto que lee el texto y el sujeto que siente y percibe el mundo son un único y mismo sujeto en convergencia, una síntesis de materiaenergía y de espíritu: una conciencia encarnada.

6.4. La lectura académica, distante y autocontrolada, no puede considerarse por ende como universal, y sobre todo no como primera o primaria. En el origen de la práctica lectora se encuentra, al contrario, la experiencia del "delirio pasivo de cosa a la que mueven", descrito por Pessoa (2002: 278), o la "pulsación en todo el cuerpo", analizada por Handke (1990: 30), que el texto induce y que es el estímulo inicial de la actividad estésica de la lectura, correlato de la actividad estésica de la escritura. Bernard Noël, el perspicaz poeta francés, excelente estudioso del arte y de la literatura, resume el encuentro entre ambas actividades en la proyección concreta del cuerpo al leer, resultado de su inherente sensomotricidad. Lo leído se presenta ante la conciencia del lector, en efecto, pero solo después de haber recorrido e impregnado su organismo; es decir, después de haberle dado una lección corporal (Noël, 1994: 62):

No vean en lo que acabo de decir una simple imagen: ustedes saben que se trata de la expresión del más concreto de los movimientos.

\footnotetext{
${ }^{12}$ Es de lamentar que el castellano no disponga de dos sustantivos para distinguir, como sí lo hace el inglés con flesh y meat, o el francés con chair y viande, la carne del hombre, anclaje de su cuerpo propio, de la carne del animal, condenada a ser producto de consumo.
} 
Nuestro cuerpo no se proyecta solo con el pensamiento: alcanza más lejos que su piel, y se envuelve en algo en lo que se puede reconocer presencia, una presencia.

Una encarnación de vida imaginada que puede resultar tentador parodiar en ciertos casos, según cuáles sean el género literario del texto, el género sociosexual de lector, la época y el punto de vista que se adopte sobre la lectura. En el siguiente ejemplo, el punto de vista es el del pintor, cuya mordaz crítica de la vivencia literaria se explica por su paradójica y simultánea condición de competidor y colaborador del escritor en los campos sociales, muy próximos entre sí, del arte y de la literatura:

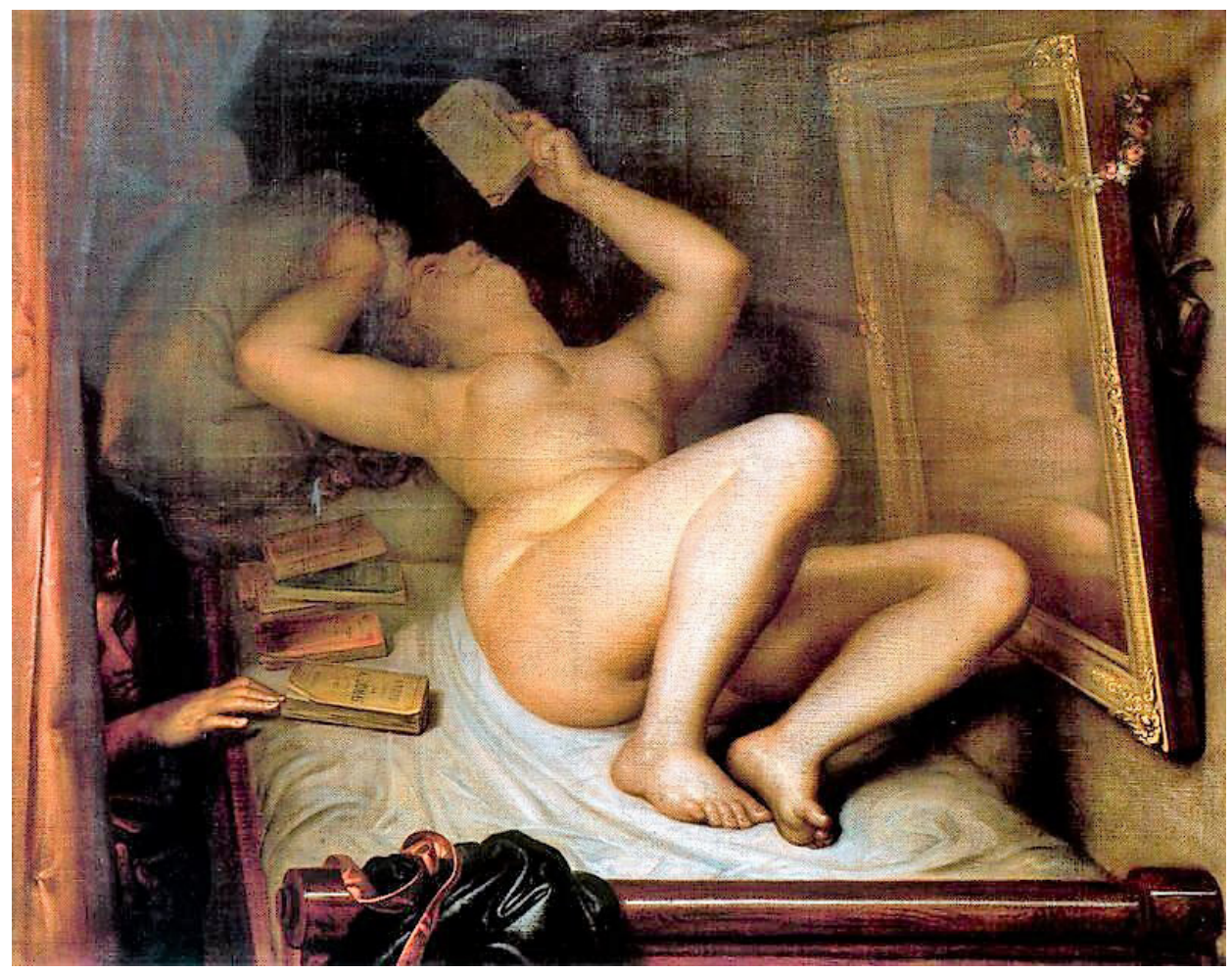

Figura 2. Anton Wiertz, La lectora de novelas, 1853. 
6.5. Únicamente los lectores profesionales, y eso tras un largo entrenamiento, alcanzan a mantener el impulso sensomotriz de la lectura bajo el control del juicio; únicamente pareja disciplina del entendimiento es capaz de reducir después a mero simulacro sígnico la comparecencia del mundo al leer. Y aun a pesar de ello, resulta entre muy difícil e imposible evitar que el cuerpo participe en la lectura cerebral, conseguir que no encarne en una re-enunciación viva el enunciado leído: la sensomotricidad se impone a través de las ligeras subvocalizaciones y gesticulaciones que, involuntariamente, se hacen cuando se lee (Golder y Gaonac'h, 2002:55) 13; y el bullicioso drama lector prosigue luego dentro del cuerpo, cambiando el movimiento propio de la lectura en un haz de tensiones, imaginarias pero eficaces, de la materia-energía somáticas. Tanto es así que dichas tensiones, si se acumulan hasta superar un umbral crítico, abandonan lo imaginario para inscribirse en la realidad, como le pasaba a Proust, cuya excitación lectora lo hacía explotar al final en movimientos vivaces, en una suerte de abreacción:

Después la última página era leida, el libro se acababa. Habia que detener la loca carrera de los ojos y de la voz que los seguía sin ruido, parándose tan solo para recuperar el aliento, con un suspiro profundo. Entonces, para dar a la agitación desencadenada en mi desde hacía demasiado tiempo otros movimientos que dirigir, me levantaba y me ponía a caminar en torno a la cama [...] (2017: 26)

\footnotetext{
${ }^{13} \mathrm{Cfr}$., también de López de Silanes y en este mismo número de Signa, el siguiente fragmento: "Diría así que la lectura, igual que otros dominios del lenguaje, lleva aparejada a nivel sensorial una sincinesia acústica, como un determinado grado de habla sub-vocal, audible solo en las primeras fases del desarrollo, cuando aprendemos a leer en voz alta, pero detectable después a escala neural por técnicas neurofisiológicas, como parte de nuestro lenguaje interior".
} 
[...] caminando, pateando, corriendo por los caminos, cada vez que acababa de cerrar el libro, en la exaltación de la lectura terminada, de las fuerzas acumuladas en la inmovilidad [...] (2017: 39)

6.6. El cuerpo-lector, atento al texto, versátil y sensible, se troca en la herramienta de una reversibilidad espontánea, durante la lectura, de lo simbólico en material, del mismo modo en que lo ha sido, durante la escritura, de lo material en simbólico. O, en otras palabras, en el cuerpolector se encarna el símbolo al igual que en el cuerpo-escritor se simboliza la carne y su posición ante el mundo. Esta es la forma en que opera, de hecho, toda producción de sentido: en el cuerpo se produce la reunión de lo que percibimos y de lo que sabemos, de lo sensible y de lo inteligible. Por ejemplo, cuando somos paisaje, porque estamos dentro de uno, en el cuerpo entran en contacto los elementos sensibles paisajísticos - las montañas, los árboles, las casas, aquel puente- y el conocimiento enciclopédico que poseemos sobre ellos - que la sierra se cultiva en terrazas, que los bosques fijan el suelo y dan cobijo a los animales pero también son objeto de explotación maderera, que los tejados se construyen allí con mucha pendiente para adaptarlos a la pluviometría, que la fábrica de hierro del puente se levantó en las postrimerías del siglo XIX con objeto de que el tren salvase el desnivel y el río, etc.-. Y al revés, al pronunciar o al leer las palabras "paisaje de montaña", es del cuerpo del locutor o del lector de donde ascienden imparables, sin premeditación ni esfuerzo, las experiencias sensoriales de la visión de un horizonte recortado, del olor a humedad y vegetación, del canto de los pájaros a lo lejos y de la profundidad espacial que sugiere, del ligero estremecimiento que en una mañana fresca acompaña un paseo por valles y quebradas, etc.

6.7. Acaso el milagro del leer pueda acabar de ponderarse si se insiste en que la lectura logra abrir, por sus solos medios, el mismo proceso semiogenético que la percepción, pero en dirección inversa a esta — desde el lenguaje a la realidad, en lugar de desde la realidad al lenguaje-; y en 
que la mentada permutabilidad experiencial de las palabras y de la materia, clave de dicho proceso semiogenético, acaece en el cuerpo del lector, cuyo trabajo específico, en tanto animal civilizado, consiste en mundificar el símbolo, haciendo mundo de palabras que previamente han simbolizado del mundo. Solo la reversibilidad de la percepción discursiva (del texto) y de la percepción natural (de la realidad) en el cuerpo sintiente y pensante - que lee iconos, visuales y verbales, de la experiencia, y que percibe experiencias iconizables - explica el fenómeno de la presentificación del mundo en la lectura ordinaria o ingenua (Ouellet, 2000: 80-107). Tal es el modo de leer que confía en el lenguaje para resucitar la vivencia porque antes la escritura ha confiado en el lenguaje para conservarla. El hombre vive y dice el mundo en un mismo gesto expresivo (Merleau-Ponty, 1945 [1976]: 203-234): para él, el continuo entre el ser y el lenguaje no es una hipótesis —un juego hermenéutico—, sino una evidencia —una práctica vital-.

6.8. La lectura suelda así la fractura entre el logos y la physis, entre la cultura y la naturaleza, entre lo inteligible y lo sensible. El leer absorto, el que nos hace ser lectura, prueba que desde el lenguaje literario, si se reúnen ciertas condiciones sociales prácticas, y si tiene lugar la animación espontánea y casi mágica de una carne lectora donde se sintetizan lo real y lo imaginario, el ser humano entra en el reino para-religioso de la plenitud de una experiencia reconciliada con su sentido ${ }^{14}$. Durante la lectura, las palabras se encarnan y son mundo; la adaptación mimética del lector a lo leído lo vuelve inherente a las presencias que el texto literario convoca; y le es entonces cumplidamente restituida la vivencia de un sentir y de un percibir inseparables de un pensar, e incluso de un actuar, por medios vicarios, esto es simbólicos. En efecto, aun cuando el pensamiento pueda $-\mathrm{y}$ deba - introducir una distancia objetivadora entre el hombre y lo que

\footnotetext{
${ }^{14}$ Solo a quienes no tengan en cuenta la mencionada confluencia paulatina de los valores religiosos y culturales en Occidente les chocará la siguiente sugerencia de Louis Marin, válida al menos para el entorno del humanismo de raíz cristiana, a propósito de la lectura: que su regla ideal es el sacramento de la eucaristía (1984: 153).
} 
el hombre lee, no por ello sería capaz la reflexión crítica de romper el vínculo primitivo que une la conciencia al ser, el lenguaje a la realidad, o el cuerpo a la acción. Pues ese vínculo ya está anudado antes de que advenga la operación reflexiva, y esta lo presupone, incluso cuando trabaja para deshacerlo, o sobre todo entonces.

\section{CREER Y CONFIAR}

7.1. Y el que tal vínculo ya esté anudado se debe a que su sólido anclaje es una fe fundacional, calificada por la fenomenología de originaria (Merleau-Ponty, 1945 [1976]): 370), y redefinida por la semiótica, con un término conjuntamente epistemológico y jurídico, como una fiducia generalizada (Greimas y Fontanille, 1991: 19, 41, 63). Una fe que postula que, si hay un mundo para el sujeto, compuesto de objetos y de otros sujetos, al que el sujeto pertenece y que le pertenece, dicho mundo ha de ser por necesidad inteligible y maniobrable; es decir, y en última instancia, humano. A partir de esa fiducia extensiva el sujeto otorga, a las cosas y a los estados del mundo, creencia; y a los otros sujetos que lo pueblan, confianza. Sin adherirse a la realidad, no cabe, de cierto, ni entenderla ni modificarla; y sin afiliarse a los otros tampoco es posible tejer intersubjetividad, la trama de mutua comprensión y adaptación recíproca que convierte al mundo en un escenario compartido. Creencia y confianza son las dos modalidades básicas de la fiducia fundamental, de una relación antropológica con el ser por la que hacemos un mundo en el ser que a su vez nos hace ser lo que somos. Y ambas cimientan la que precedentemente calificamos de seguridad ontológica del sujeto, desde la cual el sujeto enuncia, e interpreta y asume los enunciados ajenos sobre ese mundo.

7.2. Que creamos en las cosas no tiene nada de raro, ya que hacia ellas tendemos con todas nuestras fuerzas, o más bien hacia las valencias que en ellas intuimos, anticipo de los valores que después les asignaremos y reconoceremos en un único movimiento. Antonio Machado dejó escrito que "es un acto de fe toda mirada" (1988: 1276): a cada percepción la guía 
la expectativa de que no solamente hay un mundo que percibir, sino de que tiene algo que decirnos; un algo coherente en sí y, a la par, trascendente respecto de sí mismo, esto es ligado a otras percepciones igual de coherentes y de trascendentes. Semejante expectativa, que transforma en mundo el presunto o probable caos de la materia-energía primigenia, constituye una verdadera meta-creencia o creencia en la creencia, sin la cual no podrían sostenerse las creencias particulares en valencias y valores, pues es su requisito previo, su condición de posibilidad (Greimas et Fontanille, 1991: 41).

7.3. Porque depositamos una fe en los objetos y estados del mundo alimentamos también la creencia en sus representaciones verbales, y actuamos más o menos ante ellas, a través de la mimesis encarnada, como ante sus referentes mundanos. Al presuponer que los enunciados de los textos figurativos aparecen frente a nosotros dispuestos a ordenarse y a concatenarse, al igual que lo hace el mundo de la percepción, experimentamos su sentido como soporte de una presencia vivida. De ahí que, cuando se lee espontáneamente, no quepa separar la lectura del texto y la aprehensión de la realidad, o la aprehensión del texto y la lectura de la realidad, siempre articuladas entre sí en forma de quiasmo, siendo la creencia en el mundo y en las palabras dos variantes de la fiducia constitutiva en su primera modalidad. Con toda pertinencia Claudio Rodríguez considera la percepción el pórtico por el que el cuerpo accede al mismo tiempo al mundo y al lenguaje, confundido el lenguaje, circularmente, con la luz del mundo:

Y para ver hay que elevar el cuerpo, la vida entera entrando en la mirada hacia esta luz, tan misteriosa y tan sencilla, hacia esta palabra verdadera.

7.4. Y así también, mientras se halle en condiciones de seguir leyendo, el lector puede convencerse de que ese mismo mundo, del que la lectura lo ha sacado por un rato, paradójicamente "continúa de alguna 
manera" en el mundo leído (Calvino, 2013: 249). Quien lee, maticemos lo expuesto al comienzo, no se arranca sin más de la realidad al leer: antes al contrario, el lector metaforiza la realidad por vía corporal, y se la reapropia por vía intelectual, en el contramundo o antimundo leído; y el apego o desapego que, en cuanto sujeto fiduciario, siente por tal o cual género u obra literarios, define a la vez su condición como lector y como habitante del mundo compartido. Difícilmente podría ser de otro modo si todas las creencias humanas, incluso las más particulares por ejemplo, las creencias específicamente literarias-, se derivan de la creencia trascendental en la constitución significativa de la realidad, de la que aquellas no son sino manifestaciones circunstanciales ${ }^{15}$ (Luhmann, 2005: 103).

7.5. Pero para que creamos en la obra literaria no basta con que antes creamos profusamente en el mundo, su fuente y su referente últimos. La adhesión del lector a los enunciados del texto tiene además —acaso como la del observador a los objetos y estados de la realidad, que se suelen conjeturar, aun confusamente, engendrados por un Destinador inicial: Dios para los creyentes, el Ser para los filósofos, el Cosmos físico-químico para los científicos, etc.- - otra condición de posibilidad: la confianza en el enunciador del discurso que arrastra la convicción del lector, una confianza que es la segunda modalidad de la fe originaria o de la fiducia fundamental antes mencionada. A ella apuntaba Jean-Paul Sartre cuando escribió que, al leer, "nos hacemos libertad pura para dar generosamente nuestra confianza a una generosidad" (1948: 185). Aun si no se comparten el idealismo y el moralismo de esta sentencia, todavía quedará por explicar el que el lector vocacional se entregue tan serenamente a la enunciación literaria - en suma, a las palabras de otro- - con una atención, y un desistimiento

\footnotetext{
${ }^{15}$ Solo cabría juzgar "desmedida" (el calificativo es de Dufrenne, 1953a: 85) la fe que prestamos al texto en los casos en los que las competencias episemióticas o metasemióticas del lector -sus conocimientos generales de la función simbólica- están perturbadas. Las dos más conocidas patologías de causación literaria que esa perturbación puede provocar son, según la propia literatura y como se sabe, el quijotismo y el bovarismo.
} 
parcial de sí, que en otras prácticas sociales se tendrían por imprudentes, cuando no por temerarios.

7.6. La confianza que nos merece el enunciador literario y su enunciación, y que nos lleva a sentirnos unidos a él, no se explica solo por razones psicológicas. Y eso a pesar de que los seres humanos tengamos, como parece, una propensión neurobiológica, inscrita en el cuerpo socializado, a confiar en los otros, justamente porque nuestro lento desarrollo psicosocial nos coloca, durante sus primeros estadios, bajo una entera dependencia respecto del entorno familiar (Erikson, 2000), en cuyos miembros más nos vale por tanto confiar, haciendo de necesidad virtud.

7.7. La confianza que otorgamos al enunciador literario y a su enunciación tampoco se explica únicamente por razones éticas. Y eso aun cuando toda la institución literaria asegura al lector la existencia de un repertorio de normas y valores socialmente reconocidos que funciona como garantía de la lectura. Dicha garantía permite al lector, por ejemplo, salvar el escollo que para su confianza pudiera suponer el conocimiento de la biografía del autor empírico, o la presencia en el texto de un narrador no fiable, o de personajes indignos o reprobables en cualquier sentido, y seguir leyendo, sin embargo, en tranquila aceptación de la lectura, con la docilidad que caracteriza al lector natural.

7.8. Aun siendo sin duda de peso las razones psicológicas y éticas de la confianza lectora en la enunciación literaria, hace falta algo más si se trata de que el confiar se instale sin vacilaciones. Ese suplemento condicional exigido por la fiducia verosímilmente está relacionado con los requisitos generales que tiene la constitución de una intersubjetividad simbólica. Del mismo modo en que se precisa de una fe previa en la existencia de un mundo significativo para creer en el sentido de la figuración textual de un contramundo, así también se demanda una fe antecesora en la humanidad hablante para confiar en que las palabras de las obras literarias nacen de una voluntad de anudar entre los hombres un lazo firme, más antropológico que social, y más trascendental que histórico. Cabe pensar dicho lazo, se ha hecho antes y es de sobra conocido, ya como un principio de coo- 
peración comunicativa entre el escritor y el lector - unas reglas compartidas de construcción del sentido (Grice, 1973)—, ya como un principio de caridad - una consigna sobre la conveniencia de procurar entender al otro, al escritor (Davidson, 1984) — . Y ello con independencia de las faltas que contra tales dos principios vinculantes, de cooperación o de caridad, puedan cometer tanto los autores que juegan, por poética o por política, a maltratar a sus lectores, como los propios lectores que, en ciertas circunstancias, se divierten tergiversando o malinterpretando a sus autores.

7.9. Contra lo que pudiera ver en ella el precavido sentido común, la confianza concedida de antemano por el lector al enunciador literario tal vez es una manifestación más de la racionalidad social. Las sociedades humanas son tan complejas, y están tan densamente organizadas en torno a la circulación no solo de bienes, sino asimismo de signos (Lévi-Strauss, 1950 [2012]), que sin confianza entre sujetos, sin substituir el imposible control sobre los demás por una esperanza razonable de que se alcanzarán acuerdos y se cumplirán los compromisos en beneficio de todos, no sería posible su funcionamiento. Al igual que sucede en la circulación de bienes, en la comunicación literaria como circulación de signos la confianza, e incluso la metaconfianza, la confianza en la confianza en cuanto pacto tácito, precontractual, entre partes, reduce también, al menos imaginariamente, las incertidumbres y los riesgos. De ahí que haya toda una serie de estrategias literarias y paraliterarias (captatios benevolentiae, prefacios, postfacios, entrevistas, conferencias, etc.) que se destinan a consolidar la metaconfianza en que merece la pena confiar en el enunciador literario, y cooperar con él sobre la base de una (buena) fe compartida. O que más bien nos incitan, de hecho, a ponernos mansa y provisionalmente en sus manos, por decirlo con Martin Seel $(2010 ; 2011)$, pues al cabo es el enunciador quien programa el curso de los enunciados, y quien prevé los efectos que habrán de ejercer sobre el lector. Remisión de sí al enunciador que se antojaría desvarío si no fuera porque, del mismo modo en que la confianza ofrece, en el mercado económico, la ventaja de simplificar la decisión y de ampliar el radio de acción del sujeto, en el mercado simbólico, el de la 
lectura, proporciona a quien confía al menos tres rendimientos, que casi dejan pequeños a los anteriores. Veámoslos.

7.10. Primero, confiar en el enunciador literario y en su enunciación permite al lector ampliar vicariamente su experiencia de vida, por lo común muy limitada, y acceder, por vía de una presentación o presentificación a la que se adhiere, a otras experiencias más ricas y mejor elaboradas, tanto desde el punto de vista pasional como cognitivo, que las propias e inmediatas. La lectura ensancha el mundo conocido. Tal es la función de los contramundos o antimundos literarios.

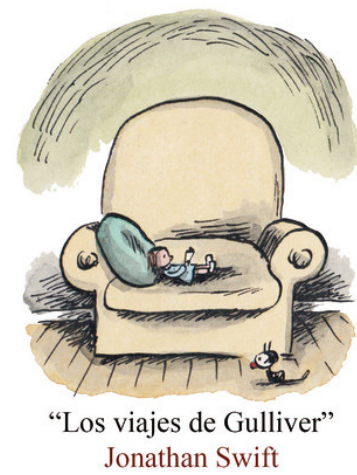

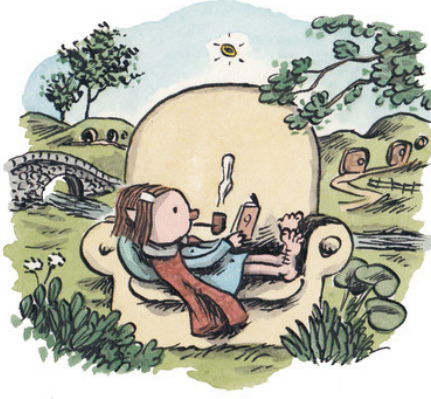

"El Hobbit"

J. R. R. Tolkien

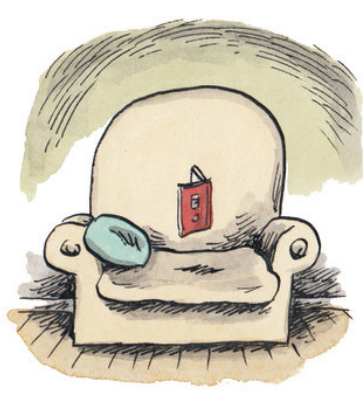

"El hombre invisible" H. G. Wells

Figura 3. Liniers, Enriqueta leyendo (C).

7.11. Segundo, confiar en el enunciador literario y en su enunciación hace posible que la relación intersubjetiva anudada con él, verdadero responsable de ese sofisticado trabajo de despliegue de experiencia, quede depurada de sus aspectos potencialmente dañinos, justo de aquellos que empujaron a Hegel a calificar el encuentro entre conciencias, en muchos contextos prácticos, de drama potencialmente mortífero (Hegel, 2017: 95100). La lectura ensancha el mundo conocido e invita a recorrerlo de la mano de otro sujeto.

7.12. Y, tercero, además de consistir en la producción de experiencias imaginarias, a la vez en cooperación con el escritor y en dependencia respecto de él, la lectura transmite al lector una vivencia de la verdad de 
esas experiencias, entendida como acuerdo intersubjetivo sobre su sentido esencial. Porque, en efecto, los seres humanos solo confiamos allí donde estimamos que la verdad es posible, esto es donde la conformidad entre sujetos sobre los significados de las cosas y de los sucesos aspira a validez general (Luhmann, 2005: 18). En el caso de la cooperación lectora, dicha validez irradia desde la lectura individual hacia la lectura colectiva: el sentido co-construido de un texto tiende, por su misma naturaleza social, a extenderse más allá del lector y del escritor hasta abarcar, virtualmente, a toda la comunidad lectora, o a un amplio segmento de esta. Ello justifica, a buen seguro, el entusiasmo proselitista de tantos lectores vocacionales, muy a menudo empeñados en que otros descubran y compartan la experiencia de la verdad adquirida durante sus lecturas predilectas. La lectura ensancha el mundo conocido, e invita a recorrerlo de la mano de otro sujeto, a la búsqueda de la verdad... De una verdad que en las páginas iniciales definimos, con mayor precisión, como una vida verdadera; o, si se prefiere, como su forma significativa; o, al menos, como su prefiguración intuida.

7.13. Comparado con estos tres rendimientos de la lectura asentada en la creencia en lo escrito y en la confianza en su autor, el mero "placer del texto" (Barthes, 2014), característico de las lecturas verbalistas o filologistas, se antoja derivado o secundario, cuando no irrelevante. Claro está que ni todos los individuos son por igual propensos a confiar en sus prójimos, ni lo hacen en la encarnación enunciativa de uno de ellos —el escritor-, ni devienen en lectores constantes, ni parecen susceptibles de hacerse lectura, como también adelantamos al principio. Sin embargo, dejadas de lado, por un momento, las patentes determinaciones sociales de la práctica lectora, sí cabría decir que hay un determinado tipo de sujeto que tomará la lectura por instrumento heurístico imprescindible: a través de ella descubrirá el mundo, los distintos mundos internos al mundo compartido y las vicisitudes del sentido de cada uno de esos mundos. Para ese tipo de sujeto, el leer se declina según todas las variantes léxicas de la fiducia fundamental, en el mundo y en el otro: el texto literario, a semejante lector, le hace confidencias a las que él otorga crédito, porque se fía de quien lo 
ha escrito y porque lo impulsa a ello una $f e$ inquebrantable en la literatura, a la que permanecerá fiel mientras tenga vida. Vivirá para leer y leerá para vivir, como recomendaba Flaubert.

\section{LOCURA Y CORDURA DE LA LECTURA}

8.1. ¿Significa todo lo anterior que el lector de literatura sea un ingenuo incurable de su propia ingenuidad y que, dominado por la illusio literaria como otros lo están por la illusio religiosa, confía inocentemente en fantasmas parlantes y cree en sus palabras? ¿Quiere acaso decir que se trata de un mitómano, de un sujeto absorto en el mito, en este caso el de la caverna, y que las paredes de su caverna están tapizadas de páginas donde se absorbe y se enajena? ¿Tal vez el lector espontáneo sufre de debilidad de conciencia, y acepta las fábulas que otros han creado para él, según insinuaba Galileo Galilei desde la severa razón físico-matemática, por no ser capaz de disciplinar la imaginación ni de someterla a la prueba de los hechos? ¿O bien, quizá todavía peor, es el lector natural un ciudadano inmaduro que se deja determinar desde fuera, que se rinde, influenciable y vulnerable como cualquiera que crea y confíe, a la más poderosa voluntad del escritor? Casi seguro que algo hay de todo ello en la lectura literaria cuando, locura más o menos tolerada por la sociedad, cristaliza en una forma de vida obsesiva, y excluyente de otras formas de vida.

8.2. Pero también está al alcance del más apasionado de los lectores literarios recuperar instantáneamente la cordura, y pasar de la mansa actitud de la lectura natural a otra distante, suspicaz, analítica, que sustituya la experiencia de la presencia viva del sentido por la fría objetivación de los recursos semióticos puestos al servicio de su convocación; y que repare así la fractura estética, e imponga el mundo compartido sobre el contramundo o antimundo leído. Para lo cual basta con que el lector modifique, puntual o permanentemente, sus regímenes de creencia en el texto que tiene entre manos y de confianza en quien lo ha escrito, en función de lo que sabe sobre el género literario al que pertenezca ese texto, sobre el pacto de 
recepción que propone, sobre su contenido discursivo o incluso sobre su autor empírico; o en función de cuáles sean los fines que el lector persiga al leer, y del contexto social o institucional en el que se desenvuelva la lectura; y de otros mil factores más, internos y externos al texto, condicionantes del acto lector. Y entonces la entrega incauta del lector al texto se tornará en capitulación del texto ante el lector, y la determinación del lector por el sentido se trocará en determinación del sentido por el lector, dueño ahora de un ars legendi, de una estrategia semiótica que podrá despojar a lo escrito de sus armas - y al autor de su influencia, por supuesto-, y que dará razón a quienes proclamaban la soberanía incondicional de la lectura sobre la escritura.

8.3. Porque nadie duda, tras décadas de teoría de la lectura, de la respuesta lectora y de la recepción, de que el lector no es el blanco fácil, el destinatario inerme, de la comunicación literaria, sino un genuino actor discursivo que, además de co-construir significaciones, las interpreta, las evalúa, las comparte o las rechaza (Bertrand, 2000: 19). Parecería ocioso por tanto glosar los que ya constituyen dos axiomas del pensamiento literario de las últimas décadas: que el lector es libre, y su lectura incalculable. Una y otra pretensiones, nos tememos no obstante, en el fondo más alimentadas por el voluntarismo, por una cierta visión moral y política de la humanidad, que por el conocimiento científico.

8.4. Sea: el lector suele o puede tener la última palabra en su conversación con textos cuyas palabras, a diferencia de las suyas, están contadas y permanecen siempre idénticas. Y sin embargo, la "mágica" y "milagrosa" lectura primaria, corporal, sensible, mimética, la que produce experiencia, decanta su sentido y engendra subjetividad en la intersubjetividad, opera como condición de posibilidad $-\mathrm{y}$ esta expresión, propia de la filosofía trascendental, es probablemente la que más hemos repetido aquí- de todas las demás lecturas, de cada uno de nuestros múltiples y en ocasiones caprichosos modos de leer. A tal lectura fluida y desenvuelta le debemos el leer, y el haber leído; a ella le deberemos el continuar leyendo, sobre todo cuando nos jubilemos 
de lectores profesionales, académicos, escolásticos. E incluso, si se me permite terminar con una nota entre la comicidad y el patetismo, quizá le debamos también el que sería certero epitafio de muchos de nosotros, dirigido genéricamente a ese mundo del que nos trasterramos y en el que nos enterramos a la vez mientras hacemos pasar páginas y desciframos signos: Leyó.

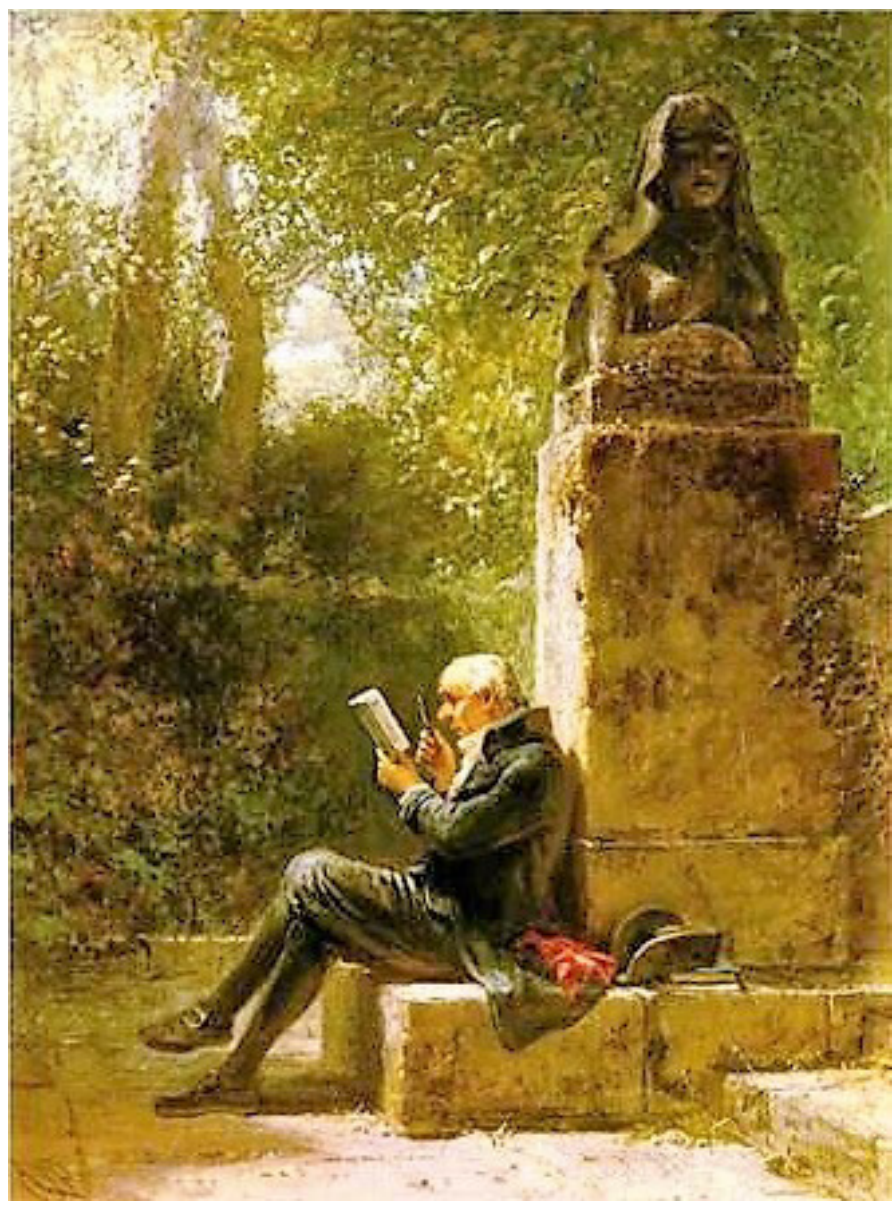

Figura 4. Carl Spitzweg, El lector en el parque, 1850. 


\section{REFERENCIAS BIBLIOGRÁFICAS}

ADORNO, Th. y HORKHEIMER, M. (1989). Sociológica. Madrid: Taurus. (2016). Dialéctica de la ilustración. Madrid: Trotta.

AIRA, C. (2016). "El don de la lectura". ABC Cultural, www.abc.es/ cultura/cultural/abci-cesar-aira-lectura-201609101749_noticia. html [06/09/2018].

BANDURA, A. (1997). Social learning theory. New York: Prentice Hall. BARTHES, R. (2014). Le plaisir du texte. París: Seuil.

BENVENISTE, E. (1976). Problèmes de linguistique générale I. París: Seuil.

BERTRAND, D. (2000). Précis de sémiotique littéraire. París: Nathan.

BOURDIEU, P. (1980). Le sens pratique. París: Éditions de Minuit. (1992). Les règles de l'art. París: Seuil. (2001). Science de la science et réflexivité. París: Raisons d'Agir.

BOURDIEU, P. et CHARTIER, R. (1984). "La lecture: une pratique culturelle". En Pratiques de lecture, R. Chartier (ed.), 265-292. París: Payot.

CALVINO, I. (2013). Si una noche de invierno un viajero. Madrid: Siruela. COQUET, J.-C. (2007). Physis et Logos. Une phénoménologie du langage. París: PUV.

DAVIDSON, D. (1984). Inquiries into Truth and Interpretation. Oxford: Clarendon Press.

DEHAENE, S. (2007). Les neurones de la lecture. París: Odile Jacob.

DUCROT, O. et SCHAEFFER, J.-M. (1995). Nouveau dictionnaire encyclopédique des sciences du langage. París: Seuil.

DUFRENNE, M. (1953a). Phénoménologie de l'expérience esthétique. Tome I: L'objet esthétique. París: PUF. (1953b). Phénoménologie de l'expérience esthétique. Tome II: La perception esthétique. París: PUF.

ERIKSON, E. (2000). El ciclo vital completado. Barcelona: Paidós. 
FLAUBERT, G. (2014). Euvres complètes. Saint Julien en Genevois: Arvensa.

FONTANILlE, J. (2004). Soma et séma. Figures du corps. París: Maisonneuve et Larose. (2011). Corps et sens. París: PUF. (2015). Formes de vie. Liège: PUL.

FONTANILLE, J. y ZILBERBERG, C. (1998). Tension et signification. Liège: Pierre Mardaga.

GADAMER, H.-G. (2012). Verdad y método. Salamanca: Ediciones Sígueme.

GREIMAS, A.-J. (1987). De l'imperfection. Périgueux: Pierre Fanlac.

GREIMAS, A.-J. et FONTANILLE, J. (1991). Sémiotique des passions. París: Gallimard.

GRICE, H. P. (1979). "Logique et conversation". Communications, 30, $57-72$.

HANDKE, P. (1990). Pero yo vivo solamente de los intersticios. Barcelona: Gedisa. (1994). Ensayo sobre el día logrado. Madrid: Alianza Tres.

HEGEL, G. W. F. (2017). Fenomenología del espiritu. México: FCE.

HUSSERL, E. (1996). Leçons pour une phénoménologie de la conscience intime du temps. París: PUF.

(2003). Recherches logiques. Tome II. París: PUF.

INGARDEN, R. (1983). L'oeuvre d'art littéraire. Lausanne: L'Âge d'Homme.

(2005). La comprehensión de la obra de arte literaria. México: Universidad Iberoamericana.

ISER, W. (1995). L'acte de lecture. Théorie de l'effet esthétique. Bruxelles: Pierre Mardaga.

LÉVI-STRAUSS, C. (1950 [2012]). Introduction à l'œuvre de Marcel Mauss. París: PUF.

LOTMAN, I. (1996). Semiosfera I. Semiótica de la cultura y del texto. Madrid: Cátedra y Universidad de Valencia. 
LUHMANN, N. (2005). Confianza. Barcelona: Anthropos.

MANGUEL, A. (2018). "Tuitepistolarios y cibercartas". Babelia 1363, 3. Madrid: El País.

MARIN, L. (1984). "Lire un tableau. Une lettre de Poussin en 1639”. En Pratiques de lecture, R. Chartier (ed.), 129-160. París: Payot.

MERLEAU-PONTY, M. Phénoménologie de la perception. París: Gallimard.

NOËL, B. (1994). Le syndrome de Gramsci. París: POL.

OATES, C. J. (1987). "Literature as Pleasure, Pleasure as Literature", http:// www.narrativemagazine.com/issues/stories-week-2015-2016/ story-week/literature-pleasure-pleasure-literature-joyce-caroloates [06/09/2018].OUELLET, P. (2000). Poétique du regard. Littérature, perception, identité. Quebec/Limoges: Presses du Septentrion/PULIM. Parret, H. (2006). Épiphanies de la présence. Limoges: PULIM.

PESSOA, F. (2002). Libro del desasosiego. Barcelona: Acantilado.

PETITOT, R. (2011). “The Morphodynamical Turn of Cognitive Linguistics". Signata 2, 61-80.

PIGLIA, R. (2005). El último lector. Barcelona: Anagrama.

PROUST, M. (1905 [2017]). Sur la lecture. Montréal: La Bibliothèque Électroniquedu Québec. Recuperado de: https://beq.ebooksgratuits. com/auteurs/Proust/Proust-lecture.pdf [06/09/2018].

QUIGNARD, P. (1997). Petits traités II. París: Gallimard.

RICOEUR, P. (1975). La métaphore vive. París: Seuil.

RICHARDSON, A. y STEEN, F. F. (eds.) (2002). Literature and the Cognitive Revolution. Poetics Today 23.1.

RIZZOLATTI, G. y SINIGAGLIA, C. (2006). Las neuronas espejo. Los mecanismos de la empatía emocional. Barcelona: Paidós.

SARTRE, J.-P.(1948 [1975]). Qu'est-ce que la littérature. París: Gallimard. SAUNDERS, G. (2013). "No me conformo con emociones ligeras". Magazine 22, 19-21.

SEEL, M. (2010). El balance de la autonomía. Barcelona: Anthropos. 
(2011). Estética del aparecer. Madrid: Katz.

VIALA, A. (1985). Naissance de l'écrivain. París: Minuit.

WEIL, S. (2006). La pesanteur et la grâce. París: La République des Lettres.

WOLF, M. (2008). Cómo aprendemos a leer. Barcelona: Ediciones B.

YOURCENAR, M. (1938 [1998]). "Comment Wang-Fô fut sauvé". En Nouvelles orientales, 9-27. París: Gallimard.

Recibido el 12 de junio de 2018.

Aceptado el 6 de septiembre de 2018. 